\title{
Female cancer awareness and screening: evaluation from tertiary hospital in Eastern India
}

\author{
Payal Banerjee Ray ${ }^{1 *}$, Amitabh Ray ${ }^{2}$
}

\begin{abstract}
${ }^{1}$ Department of Gynaecology and Obstetrics KPC Medical College and Hospital, Kolkata, West Bengal, India
${ }^{2}$ Department of Radiation Oncology, Chittaranjan National Cancer Institute, Kolkata, West Bengal, India
\end{abstract}

Received: 03 February 2022

Revised: 17 February 2022

Accepted: 18 February 2022

\section{*Correspondence:}

Payal Banerjee Ray,

E-mail: dramitabhray@gmail.com

Copyright: () the author(s), publisher and licensee Medip Academy. This is an open-access article distributed under the terms of the Creative Commons Attribution Non-Commercial License, which permits unrestricted non-commercial use, distribution, and reproduction in any medium, provided the original work is properly cited.

\begin{abstract}
Background: Cancer awareness and emphasis on preventive oncology is an essential weapon in our war against cancer. Globally the approach towards cancer awareness is non-targeted with mass media and social media coverage being unselective. This study aimed to demonstrate the disparities prevalent in society especially in a developing country with regard to cancer awareness for two of the commonest female cancers and suggested measures to increase the efficacy of awareness programs in the urban and suburban population of a typical third world Indian metropolitan city.

Methods: In a cross-sectional study conducted between January 2021 to June 2021, 119 suitable female patients attending the gynaecology OPD of a medical college and hospital were randomly selected. Informed consent was taken and their knowledge/awareness about preventive oncology in carcinoma breast and carcinoma cervix (two most common cancers in Indian women) was documented using pre tested and pre structured questionnaire. The results were analysed by suitable statistical tests.

Results: Higher education and socio-economic condition was associated with increased levels of awareness for preventive measures of carcinoma breast and carcinoma cervix. Within each educational strata, higher socio-economic status predicted for increased awareness for risk factors, screening tests and vaccination.

Conclusions: Subtle differences in the patterns and degree of awareness in common female cancers were noticed with regard to educational and socio-economic standards in the studies population. These have widespread implications in planning awareness programs in resource constrained setting to ensure most efficacious utilization of Cancer awareness and Prevention programmes.
\end{abstract}

Keywords: Breast cancer, Carcinoma cervix, Awareness, Screening mammography, Cervical cancer vaccine

\section{INTRODUCTION}

Breast and cervical cancer are the commonest female cancers in India. They constitute $14.8 \%$ and $5.4 \%$ of the total disease burden in our country. ${ }^{1}$ The highest burden of breast cancer has been observed in metropolitan cities. Over the last few years there has been an increase in the trend of incidence of breast cancer, whereas cancer of uterine cervix is on the decline. ${ }^{1}$ Both these cancers are amenable to screening and early diagnosis significantly improves the treatment outcome. A multidisciplinary approach including awareness programs, preventive measures, screening programs for early detection and availability of treatment facilities are vital for reducing both incidence and mortality of cancer in Indian women. Unfortunately, the majority of breast and uterine cervix cancers are diagnosed at a locally advanced stage. ${ }^{4}$ The main concern for medical services is the late presentation of disease, causing suboptimal outcomes and strain on the existent medical facilities necessary for providing adequate management for these conditions. Preventive oncology has still not gained ground in medical practice in 
India. It is hoped that with time, major changes will be evident in the incidence and outcomes of certain cancers with proper implementation of screening and vaccination for specific cancers. ${ }^{5}$ This prospective study was aimed to assess the awareness amongst patients attending the gynecology OPD regarding breast and cervical cancers and various aspects of preventive oncology applicable to these diseases. Finally, the study tried to associate various socio economic factors and the different knowledge scores of the study participants to design awareness and screening campaigns in the community targeting to the specific groups.

\section{METHODS}

The study was designed as an analytical cross-sectional study amongst 119 consecutive female patients attending the gynecology outpatient department (OPD) of KPC medical college in Kolkata. After taking approval from ethical committee, the data was collected from January 2021 to June 2022. Patients between ages 18 to 60 attending the gynecology OPD were administered a pre tested, pre designed, structured questionnaire regarding the awareness of certain aspects of breast cancer and cancer of the uterine cervix. Patients with history of cancer therapy either in the past or current and history of first degree relative who had undergone treatment for breast and cervical cancer were excluded from the study population to ensure homogeneity of responses with regard to baseline parameters. In order to calculate the socioeconomic status, the modified Kuppuswamy index (2021) was used. ${ }^{3}$ The questions were translated and back translated to local language before the study. After getting the written consent for participation, the interview was conducted at the OPD by the attending doctor. The data was coded and entered in Microsoft excel (version 2010) and statistical analysis was done using JASP software (version 5), keeping the level of significance at $0.05(\mathrm{p}<0.05)$. The answers were recorded as yes and no for risk factor awareness and preventive oncology questions and were scored as per the index criteria for the modified Kuppuswamy index. After data collection, the parameters of awareness regarding breast cancer and cervical cancer were analyzed with respect to socioeconomic strata of society, education level and knowledge regarding specifics of screening and preventive oncology like mammography, breast self examination (BSE), cervical Pap smear test and cervical cancer vaccine awareness. Descriptive statistics was performed using Microsoft excel and correlation analysis was performed analysis using Pearson's partial correlation on JASP2 software.

\section{RESULTS}

119 eligible female patients from urban and semi urban areas between the ages of 18 to 60 with no personal or family history of cancer were included in this crosssectional study for evaluating the degree of awareness regarding two of the commonest female cancers in India. The majority of the patients were between 30 to 40 years age $(n=41 ; 34.5 \%)$. The majority of the patients $(58.8 \%)$ were from the lower middle-class strata as per modified Kuppuswamy index used in the study. Only 10 patients had completed graduation $(8.4 \%)$ whereas 17 (14.2\%) of them were illiterate. The rest were educated to varying levels as depicted in Table 1.

Table 1: Demographic characteristics $(n=119)$.

\begin{tabular}{|c|c|c|}
\hline Parameters & & Frequency \\
\hline \multirow{9}{*}{$\begin{array}{l}\text { Age } \\
\text { distribution }\end{array}$} & $15-20$ & 21 \\
\hline & $20-25$ & 9 \\
\hline & $25-30$ & 11 \\
\hline & $30-35$ & 20 \\
\hline & $35-40$ & 21 \\
\hline & $40-45$ & 11 \\
\hline & $45-50$ & 14 \\
\hline & $50-55$ & 3 \\
\hline & $55-60$ & 9 \\
\hline \multirow{4}{*}{$\begin{array}{l}\text { Socioeconomic } \\
\text { class as per } \\
\text { modified } \\
\text { Kuppuswamy } \\
\text { index }\end{array}$} & Lower class & 7 \\
\hline & Upper lower class & 35 \\
\hline & Lower middle class & 70 \\
\hline & Upper middle class & 7 \\
\hline \multirow{6}{*}{$\begin{array}{l}\text { Educational } \\
\text { background }\end{array}$} & Graduate & 10 \\
\hline & $\begin{array}{l}\text { Intermediate or } \\
\text { diploma }\end{array}$ & 11 \\
\hline & $\begin{array}{l}\text { High school } \\
\text { certificate }\end{array}$ & 24 \\
\hline & $\begin{array}{l}\text { Middle school } \\
\text { certificate }\end{array}$ & 34 \\
\hline & $\begin{array}{l}\text { Primary school } \\
\text { certificate }\end{array}$ & 23 \\
\hline & Illiterate & 17 \\
\hline
\end{tabular}

Overall, the awareness regarding risk factors for breast cancer was $38.6 \%$ and cervical cancer was $34.4 \%$. The awareness regarding screening for breast cancer with BSE, clinical breast examination and mammography were $39.1 \%, 42.8 \%$ and $43.6 \%$ respectively. Further, knowledge regarding screening for cervical cancer was found in $55.4 \%$ of patients with $65.5 \%$ of patients demonstrating knowledge regarding cervical cancer vaccination (Table 5).

While looking at socioeconomic strata and education levels with respect to awareness regarding risk factors of breast and cervical cancer; there was a clear trend of increasing levels of awareness of breast cancer with improvement in socioeconomic status and educational levels. With $90 \%$ and $70 \%$ of graduates demonstrating awareness regarding risk factors for breast cancer and cervical cancer respectively. Illiteracy predicted for lack of awareness for both as did lower socioeconomic status (Table 2 and 3).

The penetration of concepts of preventive oncology in breast and cervical cancer among the study population by socioeconomic and educational levels was also explored. 
Table 2: Risk factor awareness and education.

\begin{tabular}{|c|c|c|c|c|}
\hline \multirow{2}{*}{ Education } & \multicolumn{2}{|c|}{ Ca breast risk awareness } & \multicolumn{2}{|c|}{ Ca cervix risk awareness } \\
\hline & Yes & No & Yes & No \\
\hline Graduate & 9 & 1 & 7 & 3 \\
\hline Intermediate/diploma & 7 & 4 & 6 & 5 \\
\hline High school & 12 & 12 & 10 & 14 \\
\hline Middle school & 10 & 24 & 9 & 25 \\
\hline Primary school & 8 & 15 & 8 & 15 \\
\hline Illiterate & 0 & 17 & 1 & 16 \\
\hline
\end{tabular}

Table 3: Risk factor awareness and socio-economic status.

\begin{tabular}{|c|c|c|c|c|}
\hline \multirow{2}{*}{ Socio-economic status } & \multicolumn{2}{|c|}{ Ca breast risk awareness } & \multicolumn{2}{|c|}{ Ca cervix risk awareness } \\
\hline & Yes & No & Yes & No \\
\hline Lower class & 1 & 6 & 2 & 5 \\
\hline Lower middle & 28 & 42 & 23 & 47 \\
\hline Upper lower & 12 & 23 & 12 & 23 \\
\hline Upper middle & 5 & 2 & 4 & 3 \\
\hline
\end{tabular}

Table 4: Knowledge about clinical breast examination (CBE) and self breast examination (SBE).

\begin{tabular}{|lll|}
\hline Parameters & CBE & SBE \\
\hline Yes & 51 & 46 \\
\hline No & 68 & 73 \\
\hline
\end{tabular}

Table 5: Awareness variation with socioeconomic status in sample population.

\begin{tabular}{|c|c|c|c|c|c|c|c|c|c|}
\hline \multicolumn{4}{|l|}{ Mammography awareness } & \multicolumn{3}{|c|}{$\begin{array}{l}\text { Cervical screening } \\
\text { awareness }\end{array}$} & \multicolumn{3}{|c|}{$\begin{array}{l}\text { Vaccine awareness } \\
\text { cervical cancer }\end{array}$} \\
\hline Education & No & Yes & Grand total & No & Yes & Grand total & No & Yes & Grand total \\
\hline Graduate & 1 & 9 & 10 & 4 & 6 & 10 & 3 & 7 & 10 \\
\hline Lower class & & 1 & 1 & 1 & & 1 & 1 & & 1 \\
\hline Lower middle class & 1 & 3 & 4 & 1 & 3 & 4 & 1 & 3 & 4 \\
\hline Upper lower class & & 2 & 2 & 1 & 1 & 2 & & 2 & 2 \\
\hline Upper middle class & & 3 & 3 & 1 & 2 & 3 & 1 & 2 & 3 \\
\hline High school certificate & 10 & 14 & 24 & 11 & 13 & 24 & 9 & 15 & 24 \\
\hline Lower middle class & 7 & 10 & 17 & 8 & 9 & 17 & 8 & 9 & 17 \\
\hline Upper lower class & 3 & 4 & 7 & 3 & 4 & 7 & 1 & 6 & 7 \\
\hline Illiterate & 17 & & 17 & 8 & 9 & 17 & 6 & 11 & 17 \\
\hline Lower class & 4 & & 4 & 2 & 2 & 4 & 1 & 3 & 4 \\
\hline Lower middle class & 9 & & 9 & 5 & 4 & 9 & 4 & 5 & 9 \\
\hline Upper lower class & 4 & & 4 & 1 & 3 & 4 & 1 & 3 & 4 \\
\hline Intermediate or diploma & 2 & 9 & 11 & 3 & 8 & 11 & 2 & 9 & 11 \\
\hline Lower middle class & & 4 & 4 & 1 & 3 & 4 & & 4 & 4 \\
\hline Upper lower class & 2 & 3 & 5 & 1 & 4 & 5 & 1 & 4 & 5 \\
\hline Upper middle class & & 2 & 2 & 1 & 1 & 2 & 1 & 1 & 2 \\
\hline Middle school certificate & 23 & 11 & 34 & 16 & 18 & 34 & 11 & 23 & 34 \\
\hline Lower middle class & 15 & 7 & 22 & 9 & 13 & 22 & 6 & 16 & 22 \\
\hline Upper lower class & 6 & 4 & 10 & 7 & 3 & 10 & 5 & 5 & 10 \\
\hline Upper middle class & 2 & & 2 & & 2 & 2 & & 2 & 2 \\
\hline Primary school certificate & 14 & 9 & 23 & 11 & 12 & 23 & 10 & 13 & 23 \\
\hline Lower class & 2 & & 2 & 1 & 1 & 2 & 1 & 1 & 2 \\
\hline Lower middle class & 7 & 7 & 14 & 7 & 7 & 14 & 7 & 7 & 14 \\
\hline Upper lower class & 5 & 2 & 7 & 3 & 4 & 7 & 2 & 5 & 7 \\
\hline
\end{tabular}


Table 6: Correlation analyses.

\begin{tabular}{|c|c|c|c|c|c|c|c|}
\hline Variables & & $\begin{array}{l}\text { Risk factors } \\
\text { awareness } \\
\text { breast } \\
\text { cancer }\end{array}$ & $\begin{array}{l}\text { Risk } \\
\text { factor } \\
\text { awareness } \\
\text { cervical } \\
\text { cancer }\end{array}$ & $\begin{array}{l}\text { Vaccine } \\
\text { awareness } \\
\text { cervical } \\
\text { cancer }\end{array}$ & $\begin{array}{l}\text { SBE } \\
\text { awareness }\end{array}$ & $\begin{array}{l}\text { Mammograp } \\
\text { hy awareness }\end{array}$ & $\begin{array}{l}\text { Cervical } \\
\text { screening } \\
\text { awareness }\end{array}$ \\
\hline \multirow{2}{*}{$\begin{array}{l}\text { Risk factors } \\
\text { awareness } \\
\text { Breast cancer }\end{array}$} & Pearson's r & - & & & & & \\
\hline & $\mathrm{P}$ value & - & & & & & \\
\hline \multirow{2}{*}{$\begin{array}{l}\text { Risk factor } \\
\text { awareness } \\
\text { cervical cancer }\end{array}$} & Pearson's r & 0.768 & - & & & & \\
\hline & $\mathrm{P}$ value & $<.001$ & - & & & & \\
\hline \multirow{2}{*}{$\begin{array}{l}\text { Vaccine } \\
\text { awareness } \\
\text { cervical cancer }\end{array}$} & Pearson's r & -0.005 & 0.042 & - & & & \\
\hline & $P$ value & 0.954 & 0.654 & - & & & \\
\hline \multirow{2}{*}{ SBE awareness } & Pearson's r & 0.079 & 0.042 & 0.140 & - & & \\
\hline & $\mathrm{P}$ value & 0.397 & 0.653 & 0.131 & - & & \\
\hline \multirow{2}{*}{$\begin{array}{l}\text { Mammography } \\
\text { awareness }\end{array}$} & Pearson's $\mathrm{r}$ & 0.901 & 0.680 & 0.068 & 0.170 & - & \\
\hline & $\mathrm{P}$ value & $<.001$ & $<.001$ & 0.462 & 0.065 & - & \\
\hline \multirow{2}{*}{$\begin{array}{l}\text { Cervical } \\
\text { screening } \\
\text { awareness }\end{array}$} & Pearson's r & -0.018 & -0.027 & 0.809 & -0.018 & 0.040 & - \\
\hline & $\mathrm{P}$ value & 0.849 & 0.775 & $<0.001$ & 0.848 & 0.671 & - \\
\hline
\end{tabular}

Conditioned on variables: age.

Within each educational strata, higher socioeconomic status predicted for increased awareness for screening tests and vaccination. Interestingly, a distinctly lower level of awareness for mammography was evident as opposed to cervical cancer screening or vaccination strategies amongst the study population. This was of interest given the increasing incidence of breast cancer in the urban context in India in comparison to cervical cancer which was not reflected in the awareness with regard to the cancer prevention strategies (Table 5).

The knowledge of risk factors of breast cancer correlated with risk factor awareness in cervical cancer and mammography awareness but didn't correlate to BSE awareness. Awareness regarding cervical cancer screening and vaccination correlated well. None of the other parameters studied were correlated significantly in this study (Table 6).

\section{DISCUSSION}

Cancer is a global problem. Although the third world countries still reel under the relentless onslaught of communicable disease, lifestyle related diseases were slowly catching up paralleling the global improvements in socioeconomic status and the consequent changes in diet, physical activity levels and habits. In the Indian context, the incidence of cancer had gone up significantly over the last few years. ${ }^{6}$ The commonest cancers diagnosed were head and neck cancer, carcinoma cervix and breast cancer. The usual presentation was in advanced stages burdening an encumbered health care system. ${ }^{7}$ The irony remained that most of the common cancers in India were amenable to screening. ${ }^{8}$ The large population of the country made these a very difficult task. However, increasing awareness amongst the general population regarding risk factors and screening methods of these common cancers was a possible way of trying to mitigate the problem to some extent. ${ }^{9}$

We tried to understand the awareness of risk factors, screening methods and prevention strategies for breast and cervical cancer amongst patients attending the gynecology OPD of our institute. The reason for excluding patients with past history and family history of cancer was to eliminate bias and get a clearer picture of the population awareness regarding these parameters.

The demographic profile of the ladies attending the OPD was representative of the population distribution according to age amongst women in India. ${ }^{10} \mathrm{We}$ excluded pediatric and geriatric patients as these populations also were at risk for other cancers which were not always screen detectable. We decided to use the modified Kuppuswamy index for socio-economic stratification as this scale was suggested for urban population. ${ }^{3}$ The socioeconomic distribution and educational levels were in consonance with the patient population catered to by a medical college hospital general OPD. ${ }^{11}$ Our interest was to see the level of awareness amongst various socioeconomic sections and educational levels of the attending patient population.

Overall, the awareness regarding risk factors for breast and cervical cancers was low with less than half of the patients attending the OPD demonstrating adequate knowledge regarding the same. However, the awareness regarding 
screening tests for these cancers was significantly more. This might be a reflection of the awareness drives currently focusing on these parameters. In our country such awareness drives were undertaken by every section of the healthcare system, be it government organizations, NGOs or private healthcare facilities. ${ }^{12}$ The thrust of these programs, especially when undertaken by nongovernmental agencies was towards promotion of screening tests as well as cervical cancer vaccine as they would encourage the people to attend the healthcare facility creating a possible opportunity for generation of revenue for the organizations. This might underlie the awareness of risk factors for these cancers being much lower than screening tests for breast cancer. Also, knowledge of breast self-examination seemed to be the least amongst all the purported screening systems for breast cancer. Similarly, vaccine awareness for cervical cancer was way higher than the awareness regarding risk factors in cervical cancer with almost two thirds of our study subjects showing awareness regarding cervical cancer vaccine and only one third of them demonstrating knowledge about risk factors of cervical cancer, possibly reflecting the entry of consumerism in the paradigm of preventive oncology. Although debatable, the completeness of information reaching the general population might be as important as the recall value of advertised tests and products available in order to successfully establish preventive oncology as a weapon in our war against cancer. ${ }^{13}$

There was a predictable association of socioeconomic status and education levels with risk factor awareness in these cancers. ${ }^{14}$ This was important as the awareness drives should focus on doing these awareness programs in areas where the expected benefit of dissemination of the information is maximal. Rather than do these programs as frequently in corporate offices and urban schools and colleges, it might be prudent to plan the same in slum areas and semiurban and rural educational institutions on a more regular basis. Our data supported such an approach by the regulatory authorities and government and private healthcare administrators. Further, breast cancer screening awareness was lower than cervical cancer awareness in our population. This might be reflection of the patient population being selected from a gynecology OPD. However, it might also be a pointer towards increasing efforts for breast cancer awareness as this was now the commonest female cancer in the Indian population. ${ }^{15}$

\section{Limitations}

We understand the limitation of our study being confined to one OPD of one medical college in one city which may not reflect the awareness scenario for the entire country. A multicity multi-institutional study would be beneficial in this regard to gain further insights into the issues raised thereby creating a robust wealth of usable date for implementation of preventive oncology in our country.

\section{CONCLUSION}

Cancer awareness is a potent weapon and needs judicious use as considerable time, energy and financial deployments are necessary for the same. Data regarding the awareness of risk factors in cancers amenable to screening are as important as the tests themselves. These reinforce the importance of the screening tests and empower the population against cancer in a big way. Identifying subsets of the population where preventive oncology programs will bring the maximal gains is crucial for planning and implementation of cancer awareness programs and our small study is an attempt towards drawing the medical community's attention to this facet of preventive oncology.

Funding: No funding sources

Conflict of interest: None declared

Ethical approval: The study was approved by the Institutional Ethics Committee

\section{REFERENCES}

1. Mathur P, Sathishkumar K, Chaturvedi M, Das P, Sudarshan KL, Santhappan S, et al. Cancer statistics, 2020: report from national cancer registry programme, India. JCO Glob Oncol. 2020;6:1063-75.

2. Rajaraman P, Anderson BO, Basu P, Belinson JL, Cruz AD, Dhillon PK, et al. Recommendations for screening and early detection of common cancers in India. Lancet Oncol. 2015;16(7):352-61.

3. Wani RT. Socioeconomic status scales-modified Kuppuswamy and Udai Pareekh's scale updated for 2019. J Family Med Prim Care. 2019;8(6):1846-9.

4. D'Souza ND, Murthy NS, Aras RY. Projection of cancer incident cases for India-till 2026. Asian Pac J Cancer Prev. 2013;14(7):4379-86.

5. Murthy NS, Chaudhry K, Rath GK. Burden of cancer and projections for 2016, Indian scenario: gaps in the availability of radiotherapy treatment facilities. Asian Pac J Cancer Prev. 2008;9(4):671-7.

6. Mohan S, Asthana S, Labani S, Popli G. Cancer trends in India: a review of population-based cancer registries (2005-2014). Indian J Public Health. 2018;62(3):221-3.

7. Asthana S, Patil RS, Labani S. Tobacco-related cancers in India: A review of incidence reported from population-based cancer registries. Indian $\mathrm{J} \mathrm{Med}$ Paediatr Oncol. 2016;37(3):152-7.

8. Mishra GA, Dhivar HD, Gupta SD, Kulkarni SV, Shastri SS. A population-based screening program for early detection of common cancers among women in India - methodology and interim results. Indian $\mathbf{J}$ Cancer. 2015;52(1):139-45.

9. Kumar Y, Mishra G, Gupta S, Shastri S. Cancer screening for women living in urban slums-acceptance and satisfaction. Asian Pac J Cancer Prev. 2011;12(7):1681-5.

10. Mathur P, Sathishkumar K, Chaturvedi M, Das P, Sudarshan KL, Santhappan S, et al. Cancer statistics, 
2020: report from national cancer registry programme, India. JCO Glob Oncol. 2020;6:1063-75.

11. Singh MP, Saha KB, Chand SK, Savargaonkar D. Socioeconomic determinants of community knowledge and practice in relation to malaria in highand low-transmission areas of central India. J Biosoc Sci. 2020;52(3):317-29.

12. Reichheld A, Mukherjee PK, Rahman SM, David KV, Pricilla RA. Prevalence of cervical cancer screening and awareness among women in an urban community in South India-a cross sectional study. Ann Glob Health. 2020;86(1):30.

13. Solikhah S, Promthet S, Hurst C. Awareness level about breast cancer risk factors, barriers, attitude and breast cancer screening among Indonesian women. Asian Pac J Cancer Prev. 2019;20(3):877-84.

14. Jerônimo AF, Freitas ÂG, Weller M. Risk factors of breast cancer and knowledge about the disease: an integrative revision of Latin American studies. Cien Saude Colet. 2017;22(1):135-49.

15. Agarwal G, Ramakant P. Breast cancer care in India: the current scenario and the challenges for the future. Breast Care (Basel). 2008;3(1):21-7.

Cite this article as: Ray PB, Ray A. Female cancer awareness and screening: evaluation from tertiary hospital in Eastern India. Int J Reprod Contracept Obstet Gynecol 2022;11:781-6. 